\title{
Assessment of Third Trimester Choline Phosphotransferase Activity in Uncomplicated Human Pregnancies
}

\author{
NEIL L. SASS, ${ }^{(6)}$ ALLEN P. KILLAM, MARK ROUNSAVILL, JAMES B. HADDOCK, \\ RICHARD E. HEATH, JR.. AND FRANK W. BOWEN, JR. \\ Clinical Investigations Service and Department of Obstetrics-Gynecology and Pediatrics, William Beaumont Army. \\ Medical Center, El Paso, Texas USA
}

\section{Summary}

CDP-choline:1,2-diglyceride choline phosphotransferase (CPT; EC 2.7.8.2) undergoes a marked surge in activity in human amniotic fluid when assayed from 30 weeks of gestation to term. The activity of this enzyme, plotted against gestational age, follows a highly significant regression correlation from which an equation can be obtained for the prediction of gestational age.

\section{Speculation}

In addition to its potential use in obstetrics, it is possible that a rapid and inexpensive assay for CPT or phosphatidic acid phosphohydrolase could be applied to pharyngeal or gastric secretions in neonates. These assays could be used to differentiate between pulmonary surfactant deficiency states and other pulmonary and cardiac disease states.

Jiminez et al. (4) have shown that human amniotic fluid phosphatidate phosphohydrolase (EC 3.1.3.4), the penultimate enzyme in the synthesis of phosphatidylcholine, experiences a surge in activity prior to the increase in the level of phosphatidylcholine in amniotic fluid. Research conducted in our laboratory has demonstrated an increase in the activity of CPT in rabbit amniotic fluid with corticosteroid administration. We have attempted to demonstrate a rise in activity of this enzyme in human amniotic fluid during the third trimester of pregnancy.

\section{MATERIALS AND METHODS}

Amniotic fluid was obtained by clinically indicated amniocentesis or via a monitoring catheter placed at parturition. Patients were informed that the additional fluid drawn would be used for investigational purposes and gave their consent. Visible blood or meconium staining in the fluid was a criterion for sample rejection. All specimens were frozen at $-40^{\circ}$ until assayed.

The reaction medium for amniotic fluid enzyme determination was constituted according to the following modification of the procedure of Zachman (5):

\begin{tabular}{lcc}
\hline Dipalmitin $(\alpha, \beta$-diglyceride $)$ & $1.25 \times 10^{-3} \mathrm{M}$ & $1.0 \mathrm{ml}$ \\
Amniotic fluid & & $1.0 \mathrm{ml}$ \\
$\mathrm{Mg}^{++}$ & $5.6 \times 10^{-3} \mathrm{M}$ & $0.1 \mathrm{ml}$ \\
$\mathrm{CDP}-\left[^{14} \mathrm{C}\right]$ choline & $5.0 \times 10^{-4} \mathrm{M}$ & $\underline{0.1 \mathrm{ml}}$ \\
Total & & $2.2 \mathrm{ml}$ \\
\hline
\end{tabular}

The constituents were incubated at $37^{\circ}$ with constant agitation for $90 \mathrm{~min}$. The reaction was terminated by addition of $0.5 \mathrm{ml}$ $10 \%$ tricholoroacetic acid. $N$-Butanol, $1.5 \mathrm{ml}$, was added to the reaction mixture and extraction was accomplished by vortexing at ambient temperature followed by centrifugation at $12,000 \times g$ for
$10 \mathrm{~min}$. One half milliliter of the butanol phase was transferred to a liquid scintillation vial containing $2.0 \mathrm{ml} \mathrm{2-ethoxyethanol} \mathrm{and}$ $10.0 \mathrm{ml}$ scintillation fluid composed of: PPO, $5.0 \mathrm{~g}$; POPOP, $0.1 \mathrm{~g}$; toluene, 1 liter.

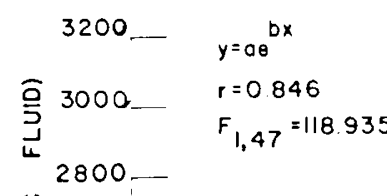

음

$\bar{\varepsilon}$

E

2

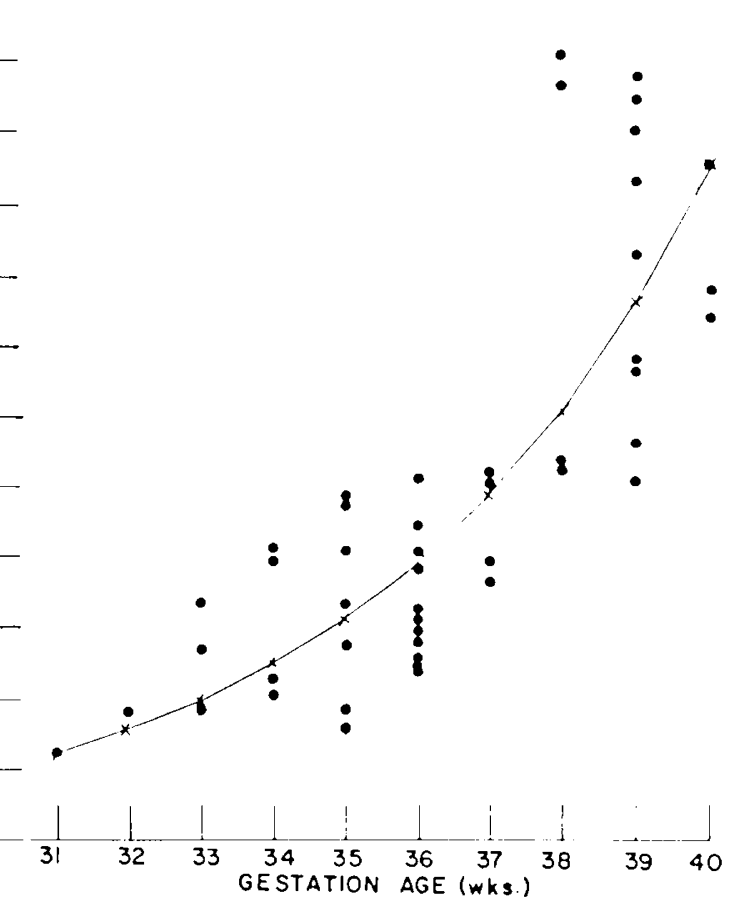

Fig. 1.

Each sample was counted three times for 5 min using a Beckman model 1650 liquid scintillation system precalibrated for ${ }^{14} \mathrm{C}$. Reagents were obtained from Sigma Chemical Company, St. Louis, MO, and New England Nuclear, Boston, MA.

\section{RESULTS AND DISCUSSION}

Choline phosphotransferase activity rises approximately 9 -fold during the third trimester of pregnancy. Calculation of a regression 


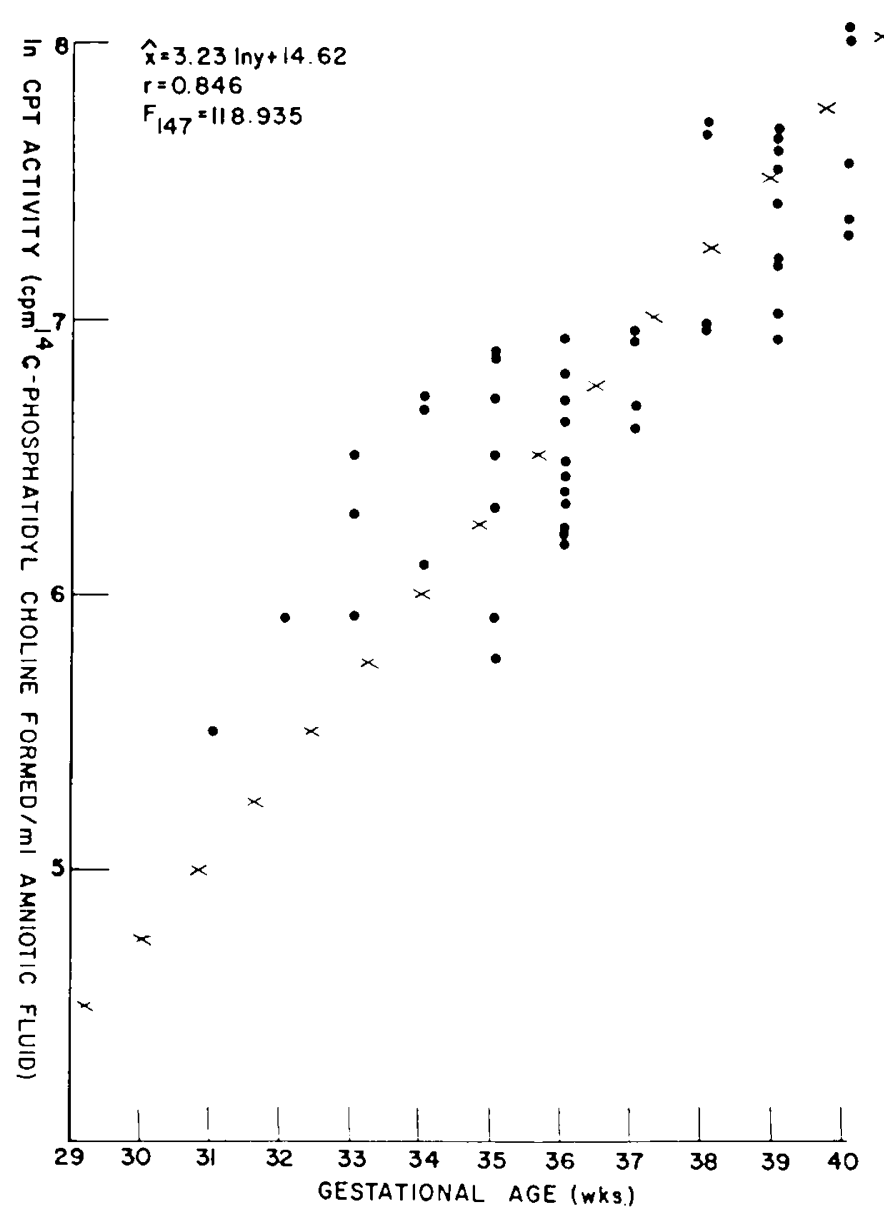

Fig. 2.

line utilizing the patient amniotic fluid enzyme activity as input resulted in a curvilinear plot (Fig. 1) which was highly correlated $(r=0.846)$ with the estimated gestational age by pediatric examination and maternal menstrual history. A test of significance was performed on the points of this line with $F_{14 i}=118.935$, indicating that the correlation between the patient CPT activity and gestational age is highly significant with $P<0.001$. By converting the enzyme activity to its natural logarithm and performing a linear regression analysis of gestational age as a function of this natural logarithm, a regression equation and line were derived (Fig. 2): $\hat{\mathrm{X}}=3.23 \ln (\mathrm{y})+14.62 ; \mathrm{Y}=\mathrm{CPT}$ activity (counts per min lecithin formed per $\mathrm{ml}$ amniotic fluid); $\hat{\mathrm{x}}=$ predicted gestational age.

This equation possesses correlation and test of significant values equal to those for the exponential regression line derived above, indicating that it can be used with a high degree of success $(P<$ 0.001 ) in predicting true gestational age.

The timing of the increase closely parallels the rise in phosphatidic acid phosphohydrolase as reported by Jiminez et al. (4). Our data indicate that the rise in CPT activity follows the rise in phosphatidic acid phosphohydrolase activity and coincides more closely with the increase in the amniotic fluid $\mathrm{L} / \mathrm{S}$ ratio at 34 weeks of gestation (3,4) (Fig. 3).

\section{CONCLUSION}

The development of a clinically useful assay is predicated upon the ability of a routine clinical laboratory to conduct the assay with ease, rapidity, a high degree of accuracy and reproducibility, and at minimum expense. The assay, for the purpose discussed here, must be at least as accurate a predictor of the degree of fetal lung maturity as the $\mathrm{L} / \mathrm{S}$ ratio both in uncomplicated and complicated pregnancies.

In cases of fetal lung immaturity, as predicted by a $\mathrm{L} / \mathrm{S}$ ratio of

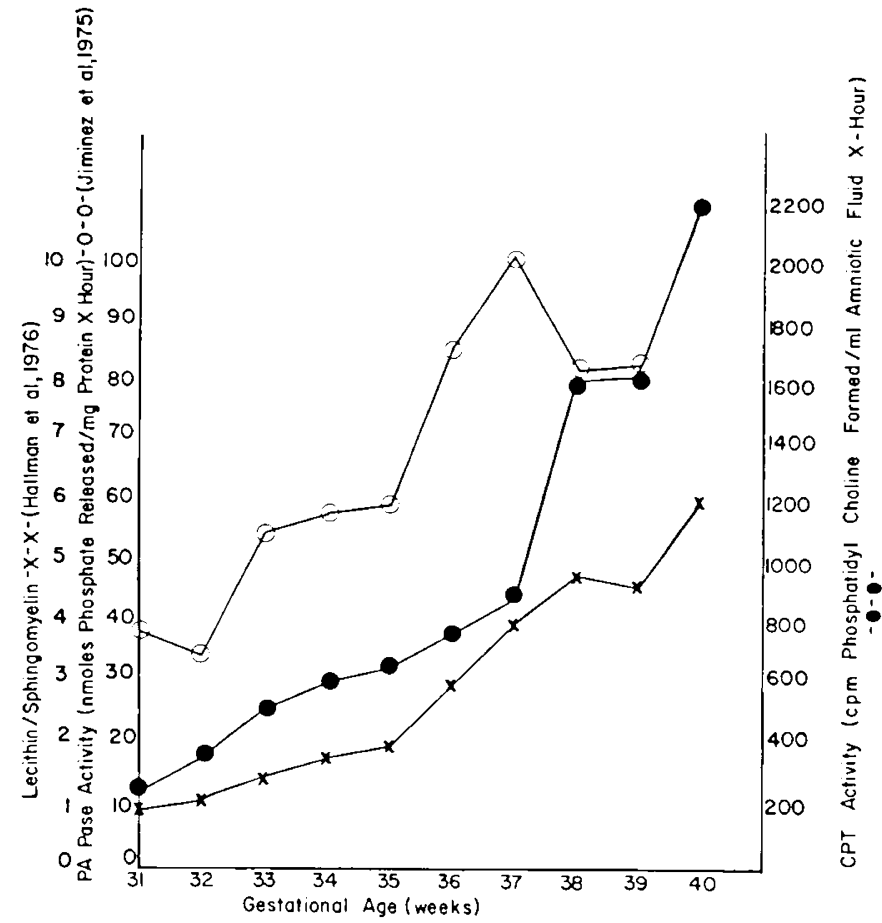

Fig. 3.

less than 2, 30\% of reported cases have no respiratory distress. It becomes clear that the $\mathrm{L} / \mathrm{S}$ ratio, although utilitarian, does possess features which reduce its credibility (1). The extremely close correlation of the assay for choline phosphotransferase with gestational age in uncomplicated pregnancies makes it potentially feasible to ascertain stages of fetal pulmonary development with a relatively rapid clinical assay. In our laboratory only one major interference was detected. Four preeclamptic patients at term treated with magnesium sulfate were found to possess extremely low CPT activity. The amniotic fluid sample was dialyzed against cold distilled water and the volume was then reduced to the predialysis level. Upon reassay, the CPT activity returned to within normal limits for the gestational age. Therefore, the presence of high concentrations of magnesium may have exhibited inhibitory properties on choline phosphotransferase. Further work is underway in this laboratory to obtain data on enzyme activity in complicated pregnancies.

\section{CONCLUSION}

A significant increase in the CPT activity of human amniotic fluid during the third trimester of uncomplicated pregnancies is reported. This increase parallels the increase in phosphatidic acid phosphohydrolase activity and the $\mathrm{L} / \mathrm{S}$ ratio and could provide the basis for an accurate prediction of fetal lung maturity.

\section{REFERENCES AND NOTES}

1. Gewolb, I. H., Hobbins, J. C., and Tan, S. Y.: Amniotic fluid cortisol as an index of fetal lung maturity. Obstet. Gynecol., 49: 462 (1977).

2. Haddock, J. B., Killam, A. P., Heath, R. E., Bowen, F., and Sass, N. L.: Choline phosphotransferase as an indicator of pulmonary maturity (Submitted for publication).

3. Hallman, M., Kulovich, M., Kirkpatrick, E., Sugarman, R. G.. and Gluck, L.: Phosphatidylinositol and phosphatidylglycerol in amniotic fluid: Indices of lung maturity. Amer. J. Obstet. Gynecol. 125: 613 (1976).

4. Jiminez, J. M., Schultz, M., and Johnson, J. M.: Fetal lung maturation. III. Amniotic fluid phosphatidic acid phosphohydrolase (PAPase) and its relation to the lecithin/sphingomyelin ratio. Obstet. Gynecol., 16: 588 (1975).

5. Zachman. R. D.: The enzymes of lecithin biosynthesis in human newborn lungs III. Phosphorylcholine glyceride transferase. Pediat. Res., 632 (1973).

6. Requests for reprints should be addressed to: Dr. Neil L. Sass. DHEW. USPHS. FDA. Bureau of Foods. HFF-190, 200 C St., S.W.. Washington. DC 20204 (U S A)

7. Received for publication May 26, 1977.

8. Accepted for publication September 16, 1977. 